UDC 519.6

$10.23947 / 2587-8999-2017-2-141-147$

\title{
New approaches to the formulation of domain decomposition method and algorithm of the large-block parallelization for mathematical modeling problems*
}

\section{V.I. Agoshkov, N.R. Lezina ${ }^{* *}$}

Institute of Numerical Mathematics Russian Academy of Sciences, Moscow State University, Moscow, Russia

Domain decomposition method based on adjoint equation and inverse problem theory is discussed. The mathematical model of the Baltic Sea circulation, developed in INM RAS, is considered. The splitting method is used for time approximations. Domain decomposition method is studied to convection-diffusion problem. Also using domain decomposition method on multiprocessor computer system is possible to create algorithms for the parallel calculations.

Keywords: domain decomposition method; inverse problems; numerical methods; adjoint equations; parallel algorithms

Introduction. For complex problems of mathematical modeling such as the problems of hydrothermodynamics of oceans and seas, methods are frequently used that make it possible to simplify the solution of a system of equations. When using the splitting method, one can reduce the solution of the system of equations to the solution of classical problems: convection-diffusion, shallow water, and elliptic problems. Quite often such problems are problems with the prevailing asymmetric operator and for them difficulties arise in the use of known methods of division of the region. Therefore, in this paper, a new approach to the formulation of methods for domain decomposition is proposed.

In addition, the development of modern computer technology makes it possible to use timeefficient algorithms of numerical realizations, which leads to the creation of parallel algorithms in solving problems numerically. One of the simplest ways to create such algorithms is to use the domain decomposition method.

1. Description of new approaches. One of the known approaches to the formulation of the method of domain decomposition is the theory of special Poincare-Steklov boundary operators introduced in [1]. These operators proved to be fruitful for constructing a wide variety of algorithms for dividing the area, analyzing and optimizing them.

Another methodology for constructing the area separation algorithms proposed in [2] is based on the theory of optimal control, the results of the theory of inverse and ill-posed problems, the

\footnotetext{
${ }^{*}$ The research is done with the financial support from the RSF (Grant 14-11-00609, within which the numerical experiments were carried out) and the RFBR (grant 16-01-00548, within which the research of the formulated tasks was carried out).

${ }^{* *}$ E-mail: agoshkov@inm.ras.ru.
} 
application of adjoint equations, and modern iterative processes. The idea of this methodology is as follows. After the introduction of the internal boundary separating the original domain, the conditions of cross-linking for solving sub-problems in subdomains are recorded on it. Then some of the stitching conditions are written through «boundary functions», which are declared "controls" and are to be found together with the solutions in subdomains. As the «closure equation», the second part of the cross-linking conditions is adopted, which are written on the inner boundary «in the sense of least squares». Thus, we obtain the optimal control problem, which is solved by already known methods (see, for example, [3-5]) and, as a result, we obtain algorithms for domain decomposition. In a sense, such an approach can be interpreted as the application of the «quasisolution method» by V.K. Ivanov» with the introduction of Tikhonov regularization for the search for «boundary functions». It should be noted that this methodology is applicable to problems with operators of different types, orders and with a different number of independent variables.

2. Consideration of the presented approach on the example of the convectiondiffusion problem. One of the basic problems of hydrothermodynamics of oceans and seas is the problem of convection-diffusion type. The application of the method of decomposition of the domain in the first stages of the solution makes it possible to reduce the process of solving the problem in the entire domain $\mathrm{D}$ to alternate solutions in subdomains $D_{1}$ and $D_{2}$, possibly having a simpler geometric form than D.

So, let's consider a problem of the form:

$$
\left\{\begin{array}{l}
T_{t}+(\bar{U}, \text { Grad }) T-\operatorname{Div}\left(v_{T} \text { GradT }\right)=f_{T} \text { on } D \times\left(t_{0}, t_{1}\right), \\
T=T(0), \quad t=t_{0} \text { in } D \\
\bar{U}_{n}^{(-)} T-v_{T} \frac{\partial T}{\partial z}+\gamma_{T}\left(T-T_{a}\right)=Q_{T}+\bar{U}_{n}^{(-)} d_{T} \text { on } \Gamma_{s} \times\left(t_{0}, t_{1}\right), \\
\frac{\partial T}{\partial N_{T}}=0 \text { on } \Gamma_{w, c} \times\left(t_{0}, t_{1}\right) \\
\bar{U}_{n}^{(-)} T+\frac{\partial T}{\partial N_{T}}=Q_{T}+\bar{U}_{n}^{(-)} d_{T} \text { on } \Gamma_{w, o p} \times\left(t_{0}, t_{1}\right), \\
\frac{\partial T}{\partial N_{T}}=0 \text { on } \Gamma_{H} \times\left(t_{0}, t_{1}\right)
\end{array}\right.
$$

with given $\bar{U}, f_{T}, \ldots, d_{T}, Q_{T}$.

Let the domain $D$ be divided by a piecewise smooth Lipschitz surface $\Gamma_{i n}$ into two subregions $D_{1}$ and $D_{2}$ so that the boundaries $\partial D_{1}$ and $\partial D_{2}$ are also Lipschitz. We denote the characteristic functions $\Gamma_{i n}$ by $m_{i n}$. Let us dwell in more detail on the conditions that must be set on the "artificially" imposed boundary of decomposition of domains $\Gamma_{i n}$. We require the following conditions:

$$
T_{1}=T_{2}, \quad \bar{U}_{n, 1}^{(-)} T_{1}+\frac{\partial T_{1}}{\partial N_{T, 1}}=-\left(\bar{U}_{n, 2}^{(-)} T_{2}+\frac{\partial T_{2}}{\partial N_{T, 2}}\right),
$$

where $\bar{U}_{n, 1}^{(-)} \equiv \bar{U}_{n}^{(-)}$, when approaching to $\Gamma_{i n}$ from $D_{i}, i=1,2$. 
Thus, problem (2.1) can be written on each of the sets $D_{1} \times\left(t_{0}, t_{1}\right), D_{2} \times\left(t_{0}, t_{1}\right)$ and conjugation conditions of the form:

$$
T_{1}=T_{2}, \quad \bar{U}_{n, 1}^{(-)} T_{1}+\frac{\partial T_{1}}{\partial N_{T, 1}}=-\left(\bar{U}_{n, 2}^{(-)} T_{2}+\frac{\partial T_{2}}{\partial N_{T, 2}}\right) \text { on } \Gamma_{i n} \times\left(t_{0}, t_{1}\right),
$$

where $N_{T, i}$ - the exterior to $\Gamma_{i n}$ the conormal $D_{i}(i=1,2)$, and $\Gamma_{i n}$ - the common part of the boundaries $\partial D_{1}$ and $\partial D_{2}$, dividing $D$ into two subregions.

Let the «additional unknown» $\mathrm{v}\left(«\right.$ control») on $\Gamma_{i n} \times\left(t_{0}, t_{1}\right)$ be entered as:

$$
v \equiv \bar{U}_{n, 1}^{(-)} T_{1}+\frac{\partial T_{1}}{\partial N_{T, 1}} \text { on } \Gamma_{i n} \times\left(t_{0}, t_{1}\right)
$$

subject to determination together with $T_{1}, T_{2}$.

As the closure equation for the problem, we consider the first equality in (2.3) and introduce the following «cost functional»:

$$
\begin{aligned}
& J_{\alpha}(v) \equiv J_{\alpha}\left(T_{1}(v), T_{2}(v), v\right) \equiv \\
& \equiv \frac{\alpha}{2} \int_{\Gamma_{\text {in }} t_{0}}^{t_{1}} \int_{i n} m_{i n}\left(v-v^{(0)}\right)^{2} d \Gamma d t+\frac{1}{2} \int_{\Gamma_{i n} t_{0}}^{t_{1}} \int_{i n}\left(T_{1}-T_{2}\right)^{2} d \Gamma d t,
\end{aligned}
$$

where $\alpha=$ const $\geq 0$ - the "regularization parameter", $v^{(0)}-$ the given function.

The following problem is posed: to find function $T_{i}$ on $D_{i} \times\left(t_{0}, t_{1}\right)$, satisfying (2.1)-(2.4) and $D \equiv D_{i},(i=1,2)$ and a function $v$ such that the functional (2.5) assumes the smallest value: $\inf _{v} J_{\alpha}(v)$.

An approximate solution of problem (2.1) is carried out with a preliminary approximation in time, for the transition to the semi-discrete form of the model and the subsequent solution of the resulting stationary equation. The solution of the problem is found by an iterative method, which will be briefly described below (in more detail this method is described in [2]). Let $v^{k}$ be already defined. Then the following steps are implemented:

1) when $v \equiv v^{k}$ solving a direct problem in $D_{i}$ to search $T_{i} \equiv T_{i}^{(k)}, i=1,2$ : 


$$
\left\{\begin{array}{l}
(\bar{U}, \text { Grad }) T_{i}-\operatorname{Div}\left(v_{T} \text { GradT }_{i}\right)+b T_{i}=F_{T} \text { in } D_{i} \times\left(t_{0}, t_{1}\right), \\
\bar{U}_{n}^{(-)} T_{i}-v_{T} \frac{\partial T_{i}}{\partial z}+\gamma_{T}\left(T_{i}-T_{a}\right)=Q_{T}+\bar{U}_{n}^{(-)} d_{T} \text { on } \Gamma_{s} \times\left(t_{0}, t_{1}\right), \\
\frac{\partial T_{i}}{\partial N_{T}}=0 \text { on } \Gamma_{w, c} \times\left(t_{0}, t_{1}\right), \\
\bar{U}_{n}^{(-)} T_{i}+\frac{\partial T_{i}}{\partial N_{T, i}}=Q_{T}+\bar{U}_{n}^{(-)} d_{T} \text { on } \Gamma_{w, o p} \times\left(t_{0}, t_{1}\right), \\
\frac{\partial T_{i}}{\partial N_{T}}=0 \text { on } \Gamma_{H} \times\left(t_{0}, t_{1}\right), \\
\bar{U}_{n, 1}^{(-)} T_{1}+\frac{\partial T_{1}}{\partial N_{T, 1}}=v, \bar{U}_{n, 2}^{(-)} T_{2}+\frac{\partial T_{2}}{\partial N_{T, 2}}=-v \text { on } \Gamma_{i n} \times\left(t_{0}, t_{1}\right)
\end{array}\right.
$$

2) solving the conjugate problem in $D_{i}$ for $T_{i} \equiv T_{i}^{(k)}, i=1,2$

$$
\left\{\begin{array}{l}
-\operatorname{Div}\left(\bar{U}, T_{i}^{*}\right)-\operatorname{Div}\left(v_{T} G r a d T_{i}^{*}\right)=0 \text { in } D_{i} \times\left(t_{0}, t_{1}\right), \\
\bar{U}_{n}^{(+)} T_{i}^{*}-v_{T} \frac{\partial T_{i}^{*}}{\partial z}+\gamma_{T} T_{i}^{*}=0 \text { on } \Gamma_{s} \times\left(t_{0}, t_{1}\right), \\
\frac{\partial T_{i}^{*}}{\partial N_{T}}=0 \text { on }\left(\Gamma_{w, c} \cup \Gamma_{H}\right) \times\left(t_{0}, t_{1}\right), \\
\bar{U}_{n}^{(+)} T_{i}^{*}+\frac{\partial T_{i}^{*}}{\partial N_{T, i}}=0 \text { on } \Gamma_{w, o p} \times\left(t_{0}, t_{1}\right) \\
\bar{U}_{n}^{(+)} T_{1}^{*}+\frac{\partial T_{1}^{*}}{\partial N_{T, 1}}=m_{i n}\left(T_{1}-T_{2}\right) \text { on } \Gamma_{i n} \times\left(t_{0}, t_{1}\right), \\
\bar{U}_{n}^{(+)} T_{2}^{*}+\frac{\partial T_{2}^{*}}{\partial N_{T, 2}}=-m_{i n}\left(T_{1}-T_{2}\right) \text { on } \Gamma_{i n} \times\left(t_{0}, t_{1}\right)
\end{array}\right.
$$

3) we find a new approximation $v^{k+1}$ :

$$
v^{k+1}=v^{k}-\tau_{k}\left(\alpha\left(v^{k}-v^{(0)}\right)+m_{i n}\left(T_{1}^{*}-T_{2}^{*}\right)\right) \text { on } \Gamma_{i n},
$$

where the parameter $\tau_{k}$ is calculated by the formula: $\tau_{k}=\frac{1}{2} \frac{\int_{\Gamma_{i n}}\left(T_{1}-T_{2}\right)^{2} d \Gamma}{\int_{\Gamma_{i n}}\left(T_{1}^{*}-T_{2}^{*}\right)^{2} d \Gamma}$;

4) go to step 1, until the exit condition for the iterative process is fulfilled.

To test the effectiveness of the method of division of the region, a number of numerical experiments were carried out. Studies were conducted for the Baltic Sea, divided into two parts. For numerical experiments, only the problem of the propagation of heat was considered. The most interesting is the result of the temperature difference obtained using the method of division of the region $T^{(d d m)}$ and without its application $T^{(w)}$ at the interface between the two regions (depth cut). The results are shown in Fig. 1. 


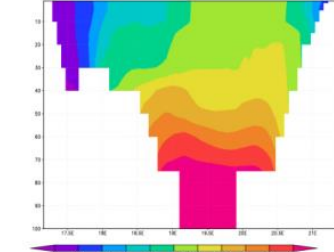

a)

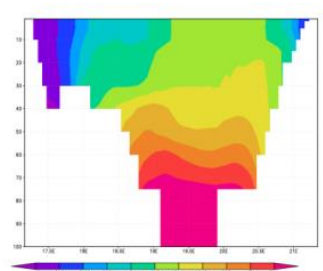

b)

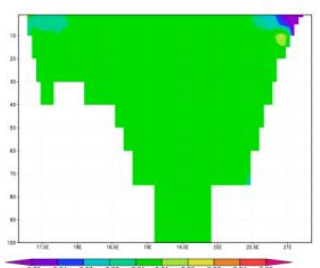

c)

Fig. 1. Temperature profile along the depth at the boundary $\Gamma_{i n}$ a) using the division method of the region; b) without using the method of division of the region;

c) the difference between the obtained temperatures $T^{(d d m)}-T^{(w)}$

Numerical experiments of comparing temperatures without and using the method of division of the region for the problem of heat distribution in the Baltic Sea show good agreement of the results. So, it is worth noting that the temperature difference $T^{(d d m)}-T^{(w)}$ at the inner boundary $\Gamma_{i n}$ is almost equal to 0 . That is, the temperature is the same.

\section{Algorithm of large-block parallelization for problems of mathematical physics on} the basis of domain decomposition method. Using the method of division of the region for problems of mathematical physics allows us to create parallel algorithms quite simply on the basis of the presented method, since the problems in the subdomains are connected only at the boundary and can be solved simultaneously.

Let us formulate a parallel algorithm for problems solved using the method of partitioning the region described above:

1. Each processor solves the problem in its subdomain;

2. After solving the problem in the subdomain, data are exchanged at the internal boundary;

3. Each processor solves the associated task in its subdomain;

4. After completion, data is exchanged at the internal boundary;

5. We find a new approximation;

6. Go to step 1 until the condition for stopping the iterative process has been fulfilled;

The acceleration for the algorithm used was approximately 1.2. A small acceleration obtained using the algorithm for the computer system "ICM RAS - the Baltic Sea" ([6]) can be explained by the fact that the model used for test checks of the algorithm is based on the method of splitting, and the splitting method (and, accordingly, the algorithm of large-block parallelization) is applied only for one module of the program for calculating the temperature in the model.

Conclusion. In addition to the above described method of dividing the region presented in this paper for the convection-diffusion problem, it should be noted that this approach can also be applied to other sub-problems that arise when the splitting method is used in hydrothermodynamics of oceans and seas. For brevity of description in this paper, a method was presented only for the convection-diffusion problem, but the approach described above can also be used for shallow-water equations, and for elliptic equations of the fourth order. More details with these methods can be found in [2]. 
Let us also make a few remarks about other approaches to constructing methods for dividing the region, different from those described above. We consider the problem (2.1). When formulating the region partition algorithm, we introduced an additional unknown $\mathrm{v}$ according to (2.4). But one could do otherwise: add an additional unknown as $T_{1}=T_{2}=v$ on $\Gamma_{i n}$, and as the "closure equation" take the second condition from (2.2). Also important is the choice of suitable space and the "appropriate rate" in it. More details on the development of algorithms and approaches to solving boundary value problems by methods of division of a domain can be found in [2].

\section{References}

1. Lebedev V.I. Generalized Schwarz algorithm with variable parameters. Lebedev, V.I. Agoshkov - M .: OVM USSR Academy of Sciences, 1981.- 50 p.

2. Agoshkov V.I. Methods of division of the region in the problems of hydrothermodynamics of oceans and seas. Agoshkov. -Moscow: IVM RAS, 2017. - 192 p.

3. Agoshkov V.I. Methods of optimal control and conjugate equations in problems of mathematical physics. Agoshkov. - Moscow: IVM RAS, 2016. - 244 p.

4. Marchuk G.I. Methods of Computational Mathematics. Marchuk. - Moscow: Nauka, 1989. $-608 \mathrm{p}$.

5. Tikhonov A.N. Methods for solving ill-posed problems. / A.N. Tikhonov, V.Ya. Arsenin Moscow: Nauka: Home Edition of Physical and Mathematical Literature, 1979. - 288 p.

6. Agoshkov V.I. Informational and computing system «IVM RAS - Baltic Sea». / Agoshkov, N.A. Aseev, N.B. Zakharova, E.I. Parmuzin, T.O. Sheloput, V.P. Shutyayev - Moscow: Institute of Computer Science, Russian Academy of Sciences, 2016. - 139 p.

\section{Authors:}

Agoshkov Valery Ivanovich, Principal Researcher of the Institute of Numerical Mathematics Russian Academy of Sciences (8 Moscow, Gubkin St., Russian Federation), Professor, Doctor of Science in Physics and Maths, Honored Scientist of the Russian Federation

Natalia Romanovna Lezina, graduate school of the Institute of Numerical Mathematics Russian Academy of Sciences (8 Moscow, Gubkin St., Russian Federation) 


\section{УДК 519.6}

\section{Новые подходы к формулировке метода разделения области и алгоритм} крупноблочного распараллеливания для задач математического моделирования*

\section{В.И. Агошков, Н.Р. Лёзина**}

ИВМ РАН, МГУ, г. Москва, Россия

В данной работе представлен метод разделения области, основанный на теории сопряженных уравнений и теории обратных задач. Используется математическая модель циркуляции Балтийского моря, разработанная в ИВМ РАН. Для аппроксимации по времени применяется метод расщепления. Метод разделения области рассмотрен на примере задачи конвекции-диффузии. Использование данного метода разделения области на многопроцессорных вычислительных системах позволяет создавать параллельные алгоритмы.

Ключевые слова: метод разделения области; обратные задачи; численные методы; сопряженные уравнения; параллельные алгоритмы

\section{Авторы:}

Агошков Валерий Иванович, главный научный сотрудник ИВМ РАН (119333, г. Москва, ул. Губкина, 8), профессор, доктор физико-математических наук, заслуженный деятель науки Российской Федерации

Наталья Романовна Лёзина, аспирант ИВМ РАН (119333, г. Москва, ул. Губкина, 8)

*Работа выполнена при поддержке РНФ (грант 14-11-00609, в рамках которого проведены численные эксперименты) и РФФИ (грант 16-01-00548, в рамках которого проведено исследование сформулированных задач).

** E-mail: agoshkov@inm.ras.ru. 